\title{
A comparative study of role of ritodrine versus magnesium sulphate in Preterm labour
}

\author{
Naagar $\mathbf{J K}^{1}$, Bindal $\mathbf{J}^{2}$ \\ ${ }^{1}$ Dr Jagrati Kiran Nagar, Assistant Professor, Department of Obstetrics and Gynecology, Bundelkhand Medical College \\ Sagar, M.P, ${ }^{2}$ Dr Jyoti Bindal, Professor and Head of the Department, Obstetrics and Gynecology, G R Medical College \\ Gwalior, M.P, India
}

Address for Correspondence: Dr Jagrati Kiran Naagar, E-mail: dr.jagratikirannaagar@gmail.com

\begin{abstract}
Introduction: Preterm delivery which accounts for over $75 \%$ of all cases of perinatal mortality and morbidity is the most important obstetric problem of world today. Present study was conducted in the Department of Obstetrics and Gynaecology at Tertiary care teaching hospital of central India over a period of one year. This study is an attempt to study the efficacy of two most commonly used tocolytic agents ritodrine versus magnesium sulphate in controlling preterm labour. Methods: The material for the present study comprised of 100 patients who were in preterm labour out of which 50 were given Ritodrine infusion and 50 were given magnesium sulphate. Both the groups were compared for tocolytic efficacy and effect of preterm labour on neonatal mortality and morbidity. Result: In the present study $>2$ days were gained in $28 \%$ in Ritodrine group and $26 \%$ in magnesium sulphate group. 3-6 days gained in $42 \%$ cases in Ritodrine group and $46 \%$ in magnesium sulphate group. It was observed that maximum time gained in both the groups in majority of cases was up to 6 days. Conclusion: The primary tocolytic agent chosen should be efficient with minimum side effects to mother and fetus. Ritodrine and magnesium sulphate appears to fulfill these requirements. Magnesium sulphate is found to be comparable to Ritodrine in terms of efficacy and safety. Magnesium sulphate appears cheaper as compare to Ritodrine.
\end{abstract}

Key words: Preterm Labour, Tocolytic agents, Magnesium sulphate, Ritodrine, Apgar Score.

\section{Introduction}

Preterm labour is defined as onset of labour before 37 completed weeks from first day of last menstrual period of mother. It is the onset of regular, painful uterine contractions, two or more per 10 minutes each lasting for at least 30 seconds with cervical effacement up to $50 \%$ or cervical dilation up to $3 \mathrm{~cm}$ between 28 to 37 completed weeks of gestation. Preterm delivery which accounts for over $75 \%$ of all cases of perinatal mortality and morbidity remains the most important obstetric problem of world today [1]. Preterm birth is the delivery of a baby before 37 completed weeks' gestation. Most mortality and morbidity affects "very preterm" infants (those born before 32 weeks' gestation), \& especially "extremely preterm" infants (those born before 28 weeks of gestation) [2].

The incidence of low birth weight in India is about $30 \%$ $40 \%$ of which $12 \%-18 \%$ are associated with gestational age less than 37 weeks. The underlying causes are unknown in nearly $50 \%$ of the cases. It is far more

Manuscript received: $3^{\text {rd }}$ Mar 2015

Reviewed:12 ${ }^{\text {th }}$ Mar 2015

Author Corrected: $66^{\text {th }}$ Apr 2015

Accepted for Publication: $11^{\text {th }}$ Apr 2015

International Journal of Medical Research and Review preferable to prevent the initiation of preterm labour than once the cascade of events has already been established [3]. According to WHO in 2005, 12.9 million births, or $9.6 \%$ of all births worldwide were preterm. Approximately 11 million (85\%) of these preterm birth were concentrated in Africa and Asia, while about 0.5 million occurred in each of Europe \& North America \& 0.9 million in Latin America and the Caribbean. The highest rates of preterm birth were in Africa, North America (11.9\% \& $10.6 \%$ respectively), and lowest were in Europe (6.2\%) [4]. Expectations of complications changes with advancing gestational age through the late preterm period. The 34 to 35 week gestational groups have increased rates of respiratory distress syndrome, sepsis and patent ductus arteriosus. At 34 weeks' gestation, relatively high rates of neonatal intensive care unit admission were noted (16.3\%), where as the admission rate decreased to $4.8 \%$ by 36 weeks' gestation [5]. Any preterm delivery, postponed by 24-72 hours, by using inhibitors of uterine contractile activity for at least 2 days, may be regarded as an optimal action of any tocolytic agent. This period gives time for glucocorticoids in enhancing lung maturity of foetus. These drugs delay the delivery and permit the use of glucocorticoids to Available online at: www.ijmrr.in 409 | P a g e 
facilitate the transfer of patient to a unit where intensive neonatal care facilities are available. Special attention was given to premature infant care as evident by development of incubators and neonatal care units. Prematurity becomes nationally visible as the most frequent cause of neonatal death

The present study is an attempt to study the efficacy of two most commonly used tocolytic agents Ritodrine Versus Magnesium Sulphate in controlling preterm labour so that a new door can be opened which will create new horizons for preterm infants.

\section{Material and Method}

This study was conducted in the Department of Obstetrics and Gynaecology at Tertiary care teaching hospital of central India over a period of one year. Study population considered of 100 patients out of whom 50 were given Ritodrine infusion (study group A) and 50 cases were given Magnesium Sulphate (study group B).

Inclusion Criteria: Patients who satisfied the following criteria-

- $\quad$ Singleton pregnancy

- Pregnancy between 24-36 weeks of gestation as calculated from last menstrual period

- Documented uterine contraction (at least 1-2 every minutes)

- Documented progression in cervical effacement and dilatation $(2-4 \mathrm{~cm})$

- Intact membranes

Exclusion Criteria: Patients were excluded from history if anyone of following is present:

- Abnormal vaginal bleeding

- Documented ruptured membranes

- Foetal disorder like foetal distress intra uterine growth retardation and Polyhydramious, maternal disorder like heart disease, APH, diabetes.

- Estimated gestational age less than 24 weeks or more than 36 weeks.

- Estimated weight less than 500 gm or more than 2500 gm.

\section{Following investigation were carried out in all cases-}

- Haemoglobin

- Blood urea

- Blood sugar

- Blood

-Grouping

-Typing

- Urine

-Routine

International Journal of Medical Research and Review
-Microscopic

Detailed history of all cases was taken. Their age, residence, literacy, occupation, socio economic status was noted. Socio economic status was based on Prasad classification. Full general examination of patient including her general condition, pulse, blood pressure, total body weight, pallor, icterus, and oedema was done.

Parenatal Ritodrine therapy was started as soon as possible after the diagnosis of preterm labour. Diagnosis of preterm labour was established by estimating uterine activity, presence of show, cervical effacement and dilatation of cervix, condition of membrane, were examined for diagnosis of premature labour.

\section{Method}

The Ritodrine infusion is prepared by dissolving $150 \mathrm{mg}$ ritodrine in $500 \mathrm{ml}$ of $5 \%$ glucose solution. Then this ritodrine hydrochloride solution is given $\mathrm{I} / \mathrm{V}$ by microdip set. Initially started at 6-8 drop/minute then drop rate was increased after every $10 \mathrm{~min}$. Till uterine contractions subsided or increases in pulse rate occurred of more than 120 beats/minutes.

Maternal blood pressure and pulse rate were recorded every 15 minutes during $1^{\text {st }}$ hour and half hourly during parentral therapy and every 4 hourly during initial oral treatment.

The therapy was discontinued if any side effects occurred. These included maternal heart rate of $>120$ beats per minute or foetal heart rate of $>200$ beats/minutes, if systolic blood pressure $>160 \mathrm{mmHg}$ or diastolic blood pressure $<40 \mathrm{mmHg}$. In addition various subjective complaints such as chest pain, shortness of breath, nausea, vomiting also considered.

Finally spontaneous rupture of membrane or progression of cervical dilatation $>4 \mathrm{~cm}$ were noted and infusion stopped at this point.

Magnesium sulphate dose scheduled: An initial loading dose of 4 grams of magnesium sulphate (4 ampules of $50 \%$ magnesium sulphate) were dissolved in $20 \mathrm{cc}$ of $5 \%$ dextrose solution. Which was given intravenous slowly over 5-10 minutes, this loading dose was followed by 4 gm in $500 \mathrm{cc}$ of $5 \%$ dextrose every 8 hourly, till symptoms of premature labour subsided, or any unacceptable side effect occurred.

Efficacy of drug was maintained by observing subsidence of uterine contraction, foetal heart sound, respiratory rate Available online at: www.ijmrr.in 410 | $\mathrm{P}$ a g e 


\section{Research Article}

of mother of at least 14/minutes, urine output more than $30 \mathrm{ml} /$ hour, presence of deep tendon reflexes, knee jerk and diastolic blood pressure not less than $100 \mathrm{mmHg}$.
Tocolysis was considered successful if contraction ceased and delivery was delayed for at least 48 hours.

\section{Result}

During study period of 12 months the overall incidence of preterm labour was $11.8 \%$. We observed that the majority of cases were between 31-32 weeks of gestational age. It was observed that maximum time gained in both the group in majority of cases was up to 6 days. Apgar score of more than 7 were observed in $70 \%$ in study group A and $64 \%$ in study group B in 1 min and $94 \%$ and $92 \%$ in study group B in 5 min. Deliveries were postponed for more than 2 days in $94 \%$ cases in study group (A). More than 20 days were gained in 14\% of patients. Maximum gained was 43 days in one patient, while in study group (B) deliveries were postponed for more than 2 days in $88 \%$ cases with magnesium sulphate treatment.

Table No 1: Incidence of Preterm labour in study population

\begin{tabular}{|l|l|l|l|}
\hline & Term delivery & Preterm delivery & Total \\
\hline No. Of cases & 2207 & 363 & 3070 \\
\hline$\%$ of cases & $88.2 \%$ & $11.8 \%$ & $100 \%$ \\
\hline
\end{tabular}

Incidence of preterm labour was $11.8 \%$.

Table No 2: Distribution of Preterm babies

\begin{tabular}{|l|l|l|}
\hline Weeks of gestation & Number of cases & Percentage \\
\hline $27-28$ & 10 & $10 \%$ \\
\hline $29-30$ & 13 & $13 \%$ \\
\hline $31-32$ & 45 & $45 \%$ \\
\hline $33-34$ & 21 & $21 \%$ \\
\hline $35-36$ & 12 & $12 \%$ \\
\hline Total & $\mathbf{1 0 0}$ & $\mathbf{1 0 0 \%}$ \\
\hline
\end{tabular}

Maximum numbers of babies were between 31-32 weeks gestational age.

Table No 3: Showing total gain of days in both groups

\begin{tabular}{|l|l|l|l|l|l|}
\hline \multirow{2}{*}{ S. No. } & \multirow{2}{*}{ Days gained } & \multicolumn{2}{l|}{ Study group A Ritodrine } & \multicolumn{2}{l|}{$\begin{array}{l}\text { Study group B } \\
\text { Magnesium sulphate }\end{array}$} \\
\cline { 3 - 6 } & & No & $\%$ & No & $\%$ \\
\hline 1 & $<2$ & 3 & $6 \%$ & 6 & $12 \%$ \\
\hline 2 & 2 days & 11 & $22 \%$ & 10 & $20 \%$ \\
\hline 3 & $3-6$ & 20 & $40 \%$ & 21 & $42 \%$ \\
\hline 4 & $7-13$ & 7 & $14 \%$ & 7 & $14 \%$ \\
\hline 5 & $14-20$ & 2 & $4 \%$ & 5 & $10 \%$ \\
\hline 6 & $>21$ & 7 & $14 \%$ & 1 & $2 \%$ \\
\hline
\end{tabular}

In most of patients delivery was postponed for 1-2 weeks with these drugs.

Table No 4: Apgar score of babies in both group

\begin{tabular}{|c|c|c|c|c|c|c|c|c|c|}
\hline \multirow[t]{2}{*}{ S. No. } & \multirow[t]{2}{*}{ Apgar score } & \multicolumn{4}{|c|}{ Study group A } & \multicolumn{4}{|c|}{ Study group B } \\
\hline & & 1-Min. & $\%$ & 5-Min. & $\%$ & 1-Min & $\%$ & 5-min & $\%$ \\
\hline 1 & $<=7$ & 15 & 30 & 3 & 6 & 18 & 36 & 4 & 8 \\
\hline 2 & $>7$ & 35 & 70 & 47 & 94 & 32 & 64 & 46 & 92 \\
\hline
\end{tabular}

Table No 5: Success rate of Ritodrine and Magnesium Sulphate

\begin{tabular}{|l|l|l|l|l|}
\hline Result & \multicolumn{2}{l|}{$\begin{array}{l}\text { No of cases \% } \\
\text { (in study group A) }\end{array}$} & \multicolumn{2}{l|}{$\begin{array}{l}\text { No of cases \% } \\
\text { (in study group B) }\end{array}$} \\
\hline & No of cases & $\%$ & No of cases & $\%$ \\
\hline Success & 47 & 94 & 44 & 88 \\
\hline Failure & 3 & 6 & 6 & 12 \\
\hline
\end{tabular}




\section{Discussion}

Prematurity, together with its complications remains the most frequent preventable cause of neonatal loss. In an attempt to prevent the sequel of premature delivery, attention was logically centred on efforts to find safe and effective tocolytic drug. The relative safety of Ritodrine and patients acceptance of the drug side effects have been well established from the world wide clinical experiences. The common side effects are tachycardia, headache, palpitation and termers encountered during an intravenous infusion of ritodrine have been found to be well tolerated by the majority of patients.

A satisfactory pharmacological method for the prevention or treatment of preterm labour is yet to be found. It has been recognised for some time that ionic Magnesium in a sufficiently high concentration can alter myometrial contractility in vivo as well as in vitro. Very good effect seen in cases with pains and increased uterine tone.

Hence the present study was undertaken to evaluate the efficiency of Ritodrine hydrochloride and Magnesium Sulphate as a tocolytic agent in preterm labour. The efficacy of Magnesium Sulphate was analysed in relation to Ritodrine hydrochloride. The result of this study confirms previous reports about the tocolytic action of Magnesium sulphate and Ritodrine . 50 cases of diagnosed preterm labour were studied for postponement of labour by Ritodrine and 50 cases by Magnesium Sulphate.

In present study the highest incidence of preterm labour was recorded in age group of 21-25 years. Cotton and associates 1984 compared Magnesium sulphate with Ritodrine as well as with placebo and they identified little difference in outcome [6]. Faulty placentation, intrauterine infection, immunological factors, cervical incompetence, uterine factors, trauma and foetal anomalies are various groups of possible causes that lead to preterm labour [7]. Hollander and colleague used infusion dose of Magnesium sulphate that averaged $4.5 \mathrm{gm} / \mathrm{hr}$. They reported that such therapy is equivalent to Ritodrine [8]. In present study maximum number of cases are primigravida, hence our study tally with the study of above authors. Ritodrine and Magnesium Sulphate do not appear to have any detrimental effect on the foetus as evidenced by the lack of significant changes in the fetal heart rate level. Apgar scores were satisfactory and comparable to other studies. Prenatal exposure to magnesium sulphate was not associated with increased neonatal morbidity and mortality. Magnesium administered to the mother promptly crosses the placenta to achieve equilibrium in foetal serum and less so in amniotic fluid. It is reported that therapeutic magnesium sulphate for tocolysis did not alter the biophysical profile in 25 foetus studied. The neonate may be depressed only if severe hypermagnesemia exists at delivery. They have not observed neonatal compromise with intramuscular therapy with magnesium sulphate. Therefore women given high dose of magnesium sulphate must be monitored very closely for hypermagnesemia that might prove toxic to them and their foetus. Recently a possible protective effect of magnesium against cerebral palsy in very low birth weight infants is reported $[9,10]$. In the present study the mean time gained in both the groups was not significantly different These results are similar to the results of other studies [11,12]. In our study no difference was found in birth weight in relation to gestational age in both the groups.

In present study the incidence of respiratory distress syndrome was $2 \%$ in study group (A) and $4 \%$ in study group (B) so our result suggest that the use of Ritodrine and Magnesium Sulphate significantly decreases the incidence of respiratory distress syndrome. Apgar score of 7 or more was observed in $70 \%$ infant at 1 minute and $94 \%$ infants at 5 minutes in study group A. Apgar score was $64 \%$ in $1 \mathrm{~min}$. and $92 \%$ in $5 \mathrm{~min}$. was observed in study group B.These results are comparable to Amita Mahajan and Parveen Marwah's study in which70\% newborns delivered to mother receiving magnesium sulphate as a tocolytic agent had 1 minute apgar score of $8-10$ as compared to $65.22 \%$ in mothers receiving isoxsuprine. $84 \%$ neonates in group I had apgar score of 8 or more as compared to $80.43 \%$ patients in group B [12]. This reflects that both magnesium sulphate and isoxsuprine given to mothers had no adverse effects on neonatal outcome

\section{Conclusion}

It is concluded from above study that Ritodrine and Magnesium Sulphate both are very effective tocolytic agents in arresting premature pains with a few side effects and good success rate, thus reducing the incidence of preterm labour and its associated stupendous reproductive loss. The almost similarity of success rate makes it difficult to choose from both of them. However, Ritodrine has been a more established tocolytic agent. But in our study of patients, tolerance was found to be better for Magnesium Sulphate group with few side effects. Magnesium Sulphate is found to be comparable to Ritodrine hydrochloride in terms of efficacy and safety. Magnesium Sulphate appears cheaper as compared to Ritodrine. However more work is needed to support favour of Magnesium Sulphate. 
Funding: Nil, Conflict of interest: None initiated.

Permission from IRB: Yes

\section{Refernces}

1. Fuchs F . Prevention of prematurity. American Journal of Obstetrics and Gynaecology 1976;126(7):809-820.

2. Janet tucker and William McGuire. Epidemiology of preterm birth. BMJ. 2004; sep 18;329(7467):675-678.

3. Stacy beck, Daniel wojdyla, paul FA van look. The worldwide incidence of preterm birth: a systemic review of maternal mortality and morbidity. Bull WHO. 2010 Jan;88(1):31-38. doi: 10.2471/BLT.08.062554

4. Creasy RK and Merkatz IR. Prevention of preterm birth: clinical opinion. Journal of Obstetrics and Gynaecology .1990;76 2S.

5. Ryan w loftin, mounira habli, Emily a DeFranco. Late preterm birth. Rev Obstet Gynecol. 2010 winter;3(1):1019.

6. Cotton DB, Strassner HT, Hill LM et al comparision between Magnesium sulphate terbutaline and placebo. For inhibition of preterm labour. A Randomized study. J Reprod Med. 1984 Feb;29(2):92-7.

\section{Research Article}

7. Gray SE Rodis JF Lettieri L, Egan JF,VintzileosA. effect of iv Magnesium sulphate on Biophysical profile of the healthy preterm fetus. Am J Obstet. \& Gynecol. 1994 April 170(4), 1131-5.

8. Hollander D I Nagey Pupkin M J Magnesium sulphate and Ritodrone Hydrochloride a randomized comparision Am J Obstet Gynecol. 1987 Mar;156(3):631-7.

9. Nelson and Grether protective effect of magnesium against cerebral palsy in very low birth weight infants .Paediatrics1995 feb;95(2):263-9.

10. Doyle LW, Crowther CA, Middleton S,Marret S,Rouse D . Magnesuim sulphate for women at risk of preterm birth for neuroprotection of the fetus. Cochrane Database of Systematic Reviews 2009 Jan 21;(1) CD 004661.

11. Larmon JE, Ross BS and May WL, Dickerson GA, Fisher RG, Morrison JC. Oral nicardipine versus intravenous magnesium sulphate for the treatment of preterm labour. American Journal of Obstet and Gynaecol 2009.181 (6);1432-1437.

12. Amita Mahajan and Parveen Marwah. Arrest of preterm labour: A Comparative study between magnesium sulphate and isoxsuprime. International Journal of Basic and Applied Medical Sciences ISSN: 2277-2103 (Online) 2014 Vol. 4 (3) September-December, pp. 19-25.

\section{How to cite this article?}

Naagar JK, Bindal J. A comparative study of role of ritodrine versus magnesium sulphate in Preterm labour. Int J Med Res Rev 2015;3(4):409-413. doi: 10.17511/ijmrr.2015.i4.080. 